\title{
Antiproliferative effect and characterization of a novel antifungal peptide derived from human Chromogranin $\mathrm{A}$
}

\author{
RUI-FANG LI, YA-LI LU, YAN-BO LU, HUI-RU ZHANG, LIANG HUANG, \\ YANLI YIN, LIN ZHANG, SHUAI LIU, ZHIFANG LU and YANAN SUN \\ College of Biological Engineering, Henan University of Technology, Zhengzhou, Henan 450001, P.R. China
}

Received October 1, 2014; Accepted August 11, 2015

DOI: $10.3892 /$ etm.2015.2838

\begin{abstract}
CGA-N46 is a novel antifungal peptide derived from the N-terminus of human Chromogranin A, corresponding to the 31st to 76th amino acids. Further research on its activities and characteristics may be helpful for the application of CGA-N46 in medical or other situations. In the present study, the antifungal spectrum and physicochemical characteristics of CGA-N46 were investigated using an antifungal assay, its antiproliferative effects on cancer and normal cells were assessed using MTT assay and its combinatorial effect with other antibiotics was analyzed using checkerboard analysis. The results showed that CGA-N46 exhibited antifungal activity against the tested Candidas $(C$. glabrata, $C$. parapsilosis, C. krusei, C. tropicalis and $C$. albicans) at a concentration of $<0.8 \mathrm{mM}$, but had no effect on the growth of filamentous fungi or other types of fungi (Cryptococcus neoformans, Aspergillus fumigatus, Aspergillus flavus, Aspergillus niger, Fusarium moniliforme, Microsporum canis, Microsporum gypseum, Trichophyton rubrum and Trichophyton mentagrophytes), even at a concentration of $3.2 \mathrm{mM}$. CGA-N46 had an inhibitory effect on the proliferation of lung cancer A549 cells and a reversible effect on the growth of normal primary chicken embryo fibroblast cells, but no hemolytic activity on human erythrocytes at the minimum inhibitory concentration of CGA-N46 against yeasts. The antifungal activity of CGA-N46 was stable at a temperature $<40^{\circ} \mathrm{C}$ or within a broad $\mathrm{pH}$ range $(\mathrm{pH}$ 5.0-7.0). Its antifungal activity was enhanced when the peptide was used in combination with fluconazole and terbinafine. The present results indicate that CGA-N46 is a safe, physicochemically stable, antifungal peptide with anticancer cell activity that exhibits an additive effect with conventional antibiotics.
\end{abstract}

Correspondence to: Professor Rui-Fang Li, College of Biological Engineering, Henan University of Technology, 100 Lianhua Street, Zhengzhou, Henan 450001, P.R. China

E-mail: 1rf@haut.edu.cn

Key words: Chromogranin A, CGA-N46, antifungal peptide, antiproliferation, physicochemical stability, additive combination

\section{Introduction}

Fungal infections have emerged worldwide due to an increasing number of immunocompromised patients, including patients with cancer, acquired immune deficiency syndrome, solid-organ and hematopoietic stem cell transplant recipients, premature neonates and patients recovering from major surgery. Nosocomial bloodstream fungal infection remains serious among hospitalized patients (1-3). Invasive Candida are responsible for the highest mortality rates $(1,4,5)$. Candida albicans is the major fungus causing mucosal and invasive infections in humans $(3,6)$; however, an increasing number of infections caused by non-albicans Candida has also been reported (7-9). Azole drugs are commonly used to treat infections caused by Candidas; however, a number of reports have indicated that Candidas are exhibiting reduced susceptibility to azole drugs $(1,3,10)$; certain Candida species are even intrinsically resistant to them $(3,11)$. A search for novel antifungal agents has therefore been undertaken for candidiasis.

Antimicrobial peptides (AMPs) are important components of innate immunity for humans and several other forms of life. The most significant characteristic of AMPs is their broad-spectrum antimicrobial activity against bacteria, viruses and fungi, including multi-drug-resistant microbes (12-14). This antimicrobial activity is not associated with the rapid emergence of resistance $(13,15,16)$, which has become a serious problem for conventional antibiotics. Furthermore, unlike traditional antibiotics that inhibit specific biosynthetic pathways, AMPs are multi-target agents. Studies into AMPs may provide an insight into the innate immunity of invertebrates and produce templates for designing novel, broad-spectrum antibiotics that would function in humans (13); therefore, AMPs have emerged as the most promising group of candidates for the development of a new class of antibiotics $(13,15)$.

AMPs are currently the focus of extensive research in order to assess their possible use as a new class of antibiotics. Possible problems in the stability, delivery and pathogen-targeting may arise in the use of AMPs as antimicrobial agents. To improve the application of such peptides, combinations with antibiotics or other compounds are generally used to increase the in vivo activity of AMPs (17).

Chromogranin $\mathrm{A}(\mathrm{CGA})$ is a protein expressed in all types of neurons (18). A series of studies on the antimicrobial function 
of the CGA-derived peptides has been conducted (19-22). Catestatin (derived from the C-terminus of bovine CGA) is expressed in murine skin in response to injury and infection, and it has a potent antimicrobial activity against bacteria, fungi and yeast. Similar activity has also been reported for vasostatin-I (CGA1-76; corresponding to CGA residues 1-76), which can trigger the selective migration of human monocytes and eosinophils. CGA1-76 and catestatin have been described to be innate immunity components of mammals $(19,21)$. A study by Lugardon et al (19) showed that the C-terminal moiety of bovine CGA1-76 exhibited a potent antifungal activity and that the disulfide-bridge loop $\mathrm{Cys}^{17}-\mathrm{Cys}^{38}$ was crucial for its antibacterial activity, but not for the antifungal activity. In order to investigate antifungal peptides derived from human CGA, we have studied several recombinant peptides derived from the N-terminus of human CGA: CGA18-76, CGA18-66 and CGA31-76 (corresponding to human CGA residues 18-76, 18-66 and 31-76, respectively). This ongoing research has shown that CGA-N46, a derived peptide containing amino acids 31-76 of the N-terminus of human CGA, has antagonistic activity against Candida albicans (23).

AMPs have a broad spectrum of activity and can act as antibacterial, antifungal, antiviral and sometimes even as anticancer peptides. Extensive research has been performed in the field of antibacterial peptides, describing their identification, characterization and mechanism of action $(13,14,24,25)$. In order to further our ongoing search for novel antimicrobial agents that could be used in drug therapy, recombinant CGA-N46 was expressed and purified in the present study, and the activities of CGA-N46 against selected fungi, cancer cells, human erythrocytes and normal fibroblast cells, as well as the stability of CGA-N46 and its effect in combination with conventional antibiotics, were investigated.

\section{Materials and methods}

Reagents. MTT, Triton X-100, dimethylsulfoxide (DMSO), fluconazole and terbinafine were purchased from Sigma-Aldrich (Shanghai, China). All of the solvents used were of high-performance liquid chromatography grade. The water used for all experiments was supplied by a Milli- $\mathrm{Q}^{\circledR}$ water purification system from Millipore (Beijing, China).

Culture and suspensions of fungal strains. The fungal strains Candida glabrata, Candida parapsilosis, Candida krusei, Candida tropicalis, Candida albicans, Cryptococcus neoformans, Aspergillus fumigatus, Aspergillus flavus, Aspergillus niger, Fusarium moniliforme, Microsporum canis, Microsporum gypseum, Trichophyton rubrum and Trichophyton mentagrophytes were supplied by the China Academy of Chinese Medical Sciences (Beijing, China). For each experiment, strains were sub-cultured onto Sabouraud dextrose (SD) agar (Oxoid Ltd., Basingstoke, UK) at $35^{\circ} \mathrm{C}$ for between $48 \mathrm{~h}$ and 7 days, depending on the species. For yeasts, the inoculum suspension was prepared by selecting 5 colonies measuring $\geq 1 \mathrm{~mm}$ in diameter and suspending the material in $5 \mathrm{ml}$ sterile $0.85 \% \mathrm{NaCl}$. The working suspension $\left(1-5 \times 10^{3} \mathrm{CFU} / \mathrm{ml}\right)$ was established by a $1: 10$ dilution with SD broth (Oxoid Ltd.). For filamentous fungi, colonies were covered with $\sim 1 \mathrm{ml}$ sterile $0.85 \%$ saline, and the suspensions were established by gently probing the colonies with the tip of a Pasteur pipette. The resulting mixture of conidia or sporangiospores and hyphal fragments was withdrawn and transferred to a sterile tube. Heavy particles were allowed to settle for 3-5 min, and the upper homogeneous suspension was then collected and mixed. The density of the suspension was measured using a microscope. The suspension was adjusted to $0.8-10 \times 10^{4} \mathrm{CFU} / \mathrm{ml}$ by diluting with SD broth.

Cell line culture. A549 lung cancer cells (American Type Culture Collection, Manassas, VA, USA) were maintained at the Henan University of Technology (Zhengzhou, China) in RPMI-1640 medium (Gibco-BRL, Grand Island, NY, USA) supplemented with $10 \%$ fetal bovine serum (Hyclone, Rockford, IL, USA), with $100 \mathrm{U} / \mathrm{ml}$ penicillin and $100 \mu \mathrm{g} / \mathrm{ml}$ streptomycin at $37^{\circ} \mathrm{C}$ in a humidified atmosphere containing $5 \% \mathrm{CO}_{2}$. The normal primary chicken embryo fibroblasts (CEFs) from specific pathogen-free chickens (Experimental Animal Center, Jenan University of Technology, Zhengzhou, China) were isolated using a standard protocol described elsewhere (26). Fibroblasts were grown as a monolayer in Dulbecco's modified Eagle's medium (Gibco-BRL) containing $10 \%$ fetal bovine serum (Hyclone).

Antifungal assay. Minimum inhibitory concentrations (MICs) of CGA-N46 against the fungi were measured according to a modified version of the broth microdilution method of the Clinical and Laboratory Standards Institute (CLSI) (27). Briefly, CGA-N46 was serially diluted to concentrations of between $0.62 \mu \mathrm{M}$ and $3.2 \mathrm{mM}$ in $20 \mathrm{mM}$ phosphate-buffered saline (PBS) (pH 6.0), and 100- $\mu 1$ samples were dispensed into the wells of a 96-well, U-shaped plate. Each sample was mixed with $100 \mu \mathrm{l} 2 \mathrm{X}$ inoculum suspension (yeast, $1-5 \times 10^{3} \mathrm{CFU} / \mathrm{ml}$; conidia or sporangiospores, $0.8-10 \times 10^{4} \mathrm{CFU} / \mathrm{ml}$ ) of a log-phase fungal culture in SD broth. The cultures were incubated at $30^{\circ} \mathrm{C}$ without agitation: C. glabrata, C. parapsilosis, $C$. krusei, $C$.tropicalis and $C$. albicans were incubated for $48 \mathrm{~h} ;$ C. neoformans, A. fumigatus, A. flavus, A. niger and F. moniliforme were incubated for $72 \mathrm{~h} ;$ M. canis, M. gypseum, T. rubrum and T. mentagrophytes were incubated for $96 \mathrm{~h}$. The MIC was defined as the lowest peptide concentration that completely inhibited fungal growth. Cultures without CGA-N46 or SD broth were employed as positive and negative controls, respectively. Three replicates were set for each experiment.

Hemolysis assay. The hemolytic activity of CGA-N46 was determined by measuring the amount of hemoglobin released by the lysis of human erythrocytes using a modified version of the method described by Huang et al (28). Briefly, CGA-N46 was serially diluted using PBS in 96-well plates to give $100 \mu \mathrm{l}$ sample solution in each well. Human erythrocytes that had undergone anticoagulation using EDTAK2 (Sigma-Aldrich) were collected by centrifugation at $1,000 \mathrm{x}$ g for $5 \mathrm{~min}$ at $4^{\circ} \mathrm{C}$, washed twice with PBS and then diluted to a concentration of $2 \%$ in PBS. The erythrocytes (100 $\mu$ l of $2 \%$ solution) were added to each well to achieve a final concentration of $1 \%$ human erythrocytes per well, and the reactions were incubated at $37^{\circ} \mathrm{C}$ for $30 \mathrm{~min}$. Following incubation, the plates were centrifuged for $10 \mathrm{~min}$ and $100 \mu \mathrm{l}$ supernatant was 
transferred to a new 96-well, U-shaped plate. Hemoglobin release was determined by measuring the absorbance of the supernatant at a wavelength of $570 \mathrm{~nm}$. Peptide samples were diluted in a 2-fold series to determine the minimum concentration at which hemolysis occurred. Erythrocytes in PBS and $1 \%(\mathrm{v} / \mathrm{v})$ Triton-X100 were used as the negative and positive controls, respectively. The hemolysis of erythrocytes was calculated using the following formula: Erythrocyte hemolysis $=\left(\mathrm{A}_{\text {sample }}-\mathrm{A}_{\text {negative }}\right) /\left(\mathrm{A}_{\text {positive }}-\mathrm{A}_{\text {negative }}\right) \times 100 \%$.

MTT assay. Cell viability was assessed using the MTT assay, based on the reduction of MTT into formazan dye by active mitochondria (24). Briefly, $50 \mu 1$ cell suspension $\left(1 \times 10^{5} \mathrm{CFU} / \mathrm{ml}\right)$ was seeded in 96 -well microtiter plates. Following the attachment of the cells, various concentrations of CGA-N46 $(5 \mu \mathrm{l})$ were added to each well to give final concentrations of between 0.1 and $1.6 \mathrm{mM}$ for incubation at $37^{\circ} \mathrm{C}$ in $5 \% \mathrm{CO}_{2}$ for 24,48 and $72 \mathrm{~h}$. A total of $10 \mu \mathrm{l} \mathrm{MTT}$ solution ( $5 \mathrm{mg} / \mathrm{ml}$ MTT in PBS) was then added to each well and incubated for an additional $4 \mathrm{~h}$. After rinsing, $100 \mu \mathrm{l}$ DMSO was added to dissolve the MTT formazan crystals. The absorbance was read using an ELISA reader (BioTek Instruments, Inc., Winooski, VT, USA) at $490 \mathrm{~nm}$. Cultures without CGA-N46 or SD broth were appointed as the control and blank groups, respectively. The relative cellular activity was calculated according to the following equation: Cell survival $(\%$ of control $)=\left(\mathrm{A}_{\text {test }}-\mathrm{A}_{\text {blank }}\right) /\left(\mathrm{A}_{\text {control }}-\mathrm{A}_{\text {blank }}\right) \times 100$. Each experiment was repeated in triplicate.

Physicochemical stability analysis. The physicochemical stability of CGA-N46 at different temperatures and pHs was assessed. CGA-N46 was dissolved in $20 \mathrm{mM}$ PBS (pH 6.0) to form a solution $(6.4 \mathrm{mM})$. The heat stability of CGA-N46 was assessed by incubating the CGA-N46 solution at different temperatures $\left(40-100^{\circ} \mathrm{C}\right)$ for $30 \mathrm{~min}$ and then comparing the MICs of the heat-treated CGA-N46 solutions with the MIC of the control. To determine the pH-stability of CGA-N46, the $\mathrm{pH}$ of the CGA-N46 solutions was adjusted to 1.0-12.0 with $0.1 \mathrm{M} \mathrm{HCl}$ or $1 \mathrm{M} \mathrm{NaOH}$, and the solutions were maintained at room temperature. After $60 \mathrm{~min}$, the $\mathrm{pH}$ was adjusted back to 6.0 in order to assess the antifungal activity against $C$. krusei. The MIC of CGA-N46 was analyzed by the broth microdilution method of the CLSI (27). A freshly prepared CGA-N46 solution in $20 \mathrm{mM}$ PBS ( $\mathrm{pH}$ 6.0) was used as control.

Checkerboard analysis. The combination effect of CGA-N46 with conventional antibiotics was analyzed using the checkerboard method described by $\mathrm{Su}$ et al (29), with slight modification. Briefly, an inoculum of logarithmic-phase C. krusei cells $\left(1 \times 10^{3} \mathrm{CFU} / \mathrm{ml}\right)$ was cultured at $30^{\circ} \mathrm{C}$ for $20 \mathrm{~h}$ in each well of a 96 -well, U-shaped culture plate containing $100 \mu \mathrm{l} \mathrm{SD}$ broth with CGA-N46 (3.2 mM to $0.62 \mu \mathrm{M})$ or an antibiotic (10 $\mu \mathrm{M}$ to $0.1 \mathrm{nM})$ added, alone or in combination, at a specified concentration. The lowest concentration of each drug combination causing growth inhibition was plotted on an arithmetic scale and any synergy or additive effect was identified from the shape of the curve and the fractional inhibitory concentration (FIC) index. The FIC index was calculated as follows: FIC index $=\left(\mathrm{A} / \mathrm{MIC}_{\mathrm{A}}\right)+\left(\mathrm{B} / \mathrm{MIC}_{\mathrm{B}}\right)$, where $\mathrm{MIC}_{\mathrm{A}}$ and
Table I. Antifungal spectrum and MICs of CGA-N46.

\begin{tabular}{lc}
\hline Strains & MICs (mM) \\
\hline Candida glabrata & 0.8 \\
Candida parapsilosis & 0.8 \\
Candida krusei & 0.1 \\
Candida tropicalis & 0.2 \\
Candida albicans & 0.2 \\
Cryptococcus neoformans & ND \\
Aspergillus fumigatus & ND \\
Aspergillus flavus & ND \\
Aspergillus niger & ND \\
Fusarium moniliforme & ND \\
Microsporum canis & ND \\
Microsporum gypseum & ND \\
Trichophyton rubrum & ND \\
Trichophyton mentagrophytes & ND \\
\hline
\end{tabular}

ND indicates that no inhibitory activity was detected, even at a concentration of $3.2 \mathrm{mM}$. MIC, minimum inhibitory concentration.

$\mathrm{MIC}_{\mathrm{B}}$ are the MICs of drugs A and B alone, respectively, and A and $\mathrm{B}$ are the MICs of drugs A and B when used in combination, respectively (30). Drug interactions are usually classified as synergistic, additive or antagonistic on the basis of the FIC index and are defined as follows: Synergy, $\leq 0.5$; additive effect, 0.5-1.0; indifference (or no effect), 1.0-2.0; antagonism, $>2.0(29)$.

Statistical analysis. Experiments were performed three times, and experimental data were analyzed using one-way analysis of variance followed by Least Significant Difference and Duncan's tests using PASW statistical software, version 18 (SPSS, Inc., Chicago, IL, USA). The results are presented as the mean \pm standard error of the mean. $\mathrm{P}<0.01$ was considered to indicate a statistically significant difference.

\section{Results}

Antifungal activity. The antifungal activity spectrum of CGA-N46 was indicated using the MICs of CGA-N46 against the tested fungi and yeasts. As shown in Table I, CGA-N46 was active against yeasts (MICs of 0.1-0.8 mM), but had no effect on the growth of filamentous fungi, even with peptide concentrations up to $3.2 \mathrm{mM}$. The highest activity was found against $C$. krusei, with an MIC of $0.1 \mathrm{mM}$.

Hemolytic activity of CGA-N46. The hemolytic activity of CGA-N46 against the highly sensitive human erythrocytes was determined as a measure of its toxicity to mammalian cells. The release of hemoglobin was monitored by measuring the absorbance at $570 \mathrm{~nm}$. As negative and positive controls, erythrocytes in PBS without CGA-N46 and $0.1 \%$ (v/v) Triton $\mathrm{X}-100$ in PBS were employed, respectively. CGA-N46 only showed weak hemolytic activity at the concentration of $1.6 \mathrm{mM}$ (Fig. 1). 
Effect of CGA-N46 on the growth of primary CEF cells. The antiproliferative activity of CGA-N46 against normal cells was assessed by investigating the effect on normal primary CEF cells using the MTT colorimetric assay. As shown in Fig. 2, CGA-N46 promoted the growth of the cells up to $24 \mathrm{~h}$ of incubation, and the promoting effect decreased as the concentration increased $>0.2 \mathrm{mM}$. When the incubation time was extended to $48 \mathrm{~h}$ and beyond, CGA-N46 showed an inhibitory activity on cell growth, and the inhibitory activity decreased with the increasing concentration. Compared with the control, the effect of CGA-N46 on normal primary CEF cells was reversible at concentrations $<1.6 \mathrm{mM}$, and the growth promotion and inhibition were not observed at the concentration of $1.6 \mathrm{mM}$.

Effect of CGA-N46 on cancer cell proliferation. The antiproliferative activity of CGA-N46 against cancer cells was investigated using an A549 human lung cancer cell line. A549 cells were treated with different concentrations of CGA-N46 ( $0.62 \mu \mathrm{M}$ to $3.2 \mathrm{mM}$ ) for $72 \mathrm{~h}$, and $20 \mathrm{mM}$ PBS (pH 6.0) was used as a negative control. MTT was used to assess the effect of CGA-N46 on A549 cell viability. As seen in Fig. 3, the number of metabolically active cells decreased significantly as the concentration of CGA-N46 increased. The proliferation of A549 cells was inhibited by CGA-N46 in a dose-dependent manner.

Physicochemical properties. To determine the effect of the physicochemical factors heat and $\mathrm{pH}$ on the antifungal activity of CGA-N46, the MIC values of CGA-N46 against C. krusei were examined and compared following the treatment of the CGA-N46 with different temperatures and pHs. As shown in Fig. 4 , the MICs remained at $0.1 \mathrm{mM}$ at a temperature $<40^{\circ} \mathrm{C}$ or within a broad $\mathrm{pH}$ range (5.0-7.0).

Combination effect of CGA-N46 and antibiotics. The combination effects of CGA-N46 with terbinafine and fluconazole against $C$. kruse $i$ are shown in Fig. 5. The MICs of terbinafine, fluconazole and CGA-N46 alone were $6 \mu \mathrm{M}, 26 \mu \mathrm{M}$ and $0.1 \mathrm{mM}$, respectively. When terbinafine was combined with CGA-N46, the MICs were $1 \mu \mathrm{M}$ and $0.05 \mathrm{mM}$, respectively. When fluconazole and CGA-N46 were used in combination, the MICs were $13 \mu \mathrm{M}$ and $0.0458 \mathrm{mM}$, respectively. The antifungal activities of the conventional antibiotics and CGA-N46 were increased when the agents were applied in combination. The FIC indices of CGA-N46 in combination with terbinafine and fluconazole, respectively, were 0.671 and 0.959 , showing that the antifungal activities of the combinations against C. kruse $i$ were additive (FIC index 0.5-1.0).

\section{Discussion}

The majority of AMPs are alkaline cationic peptides $(25,31)$. It has been postulated that their mechanism of action against microbes involves compromising the membrane of the target organism $(14,31)$. It is generally accepted that the positive charge allows the electrostatic attraction of AMPs with the phospholipid membranes of microbes; therefore, environmental $\mathrm{pH}$ has an effect on the charges of the alkaline cationic peptides. The acidic metabolites produced by

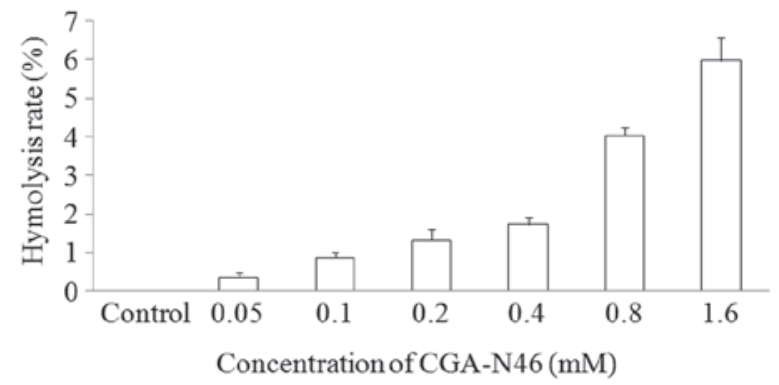

Figure 1. Hemolytic activity of CGA-N46. The minimal hemolytic concentration was determined against human red blood cells. Values are presented as the mean \pm standard error of at least three independent experiments.

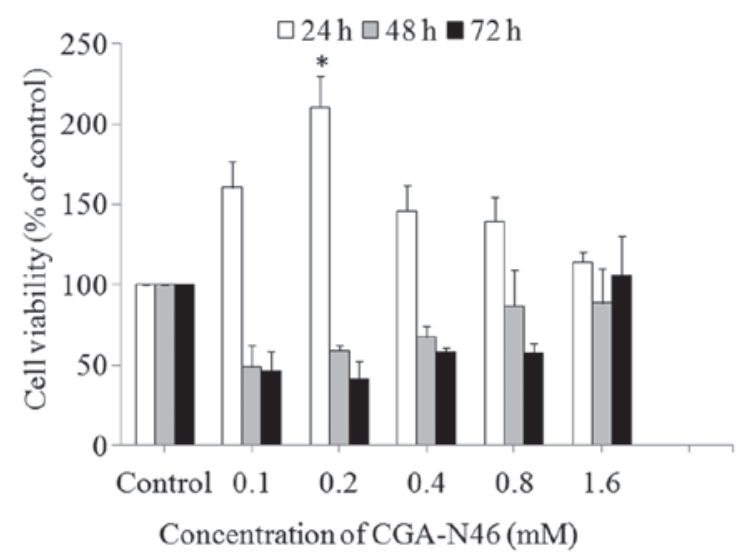

Figure 2. Effect of CGA-N46 on the growth of normal primary CEF cells. The proliferative activity of primary CEF cells was assessed using MTT assay. Values are presented as the mean \pm standard error of at least three independent experiments. $\mathrm{P}<0.01$ compared with control (one-way analysis of variance and subsequent Least Significant Difference and Duncan's tests). $\mathrm{CEF}$, chicken embryo fibroblast.

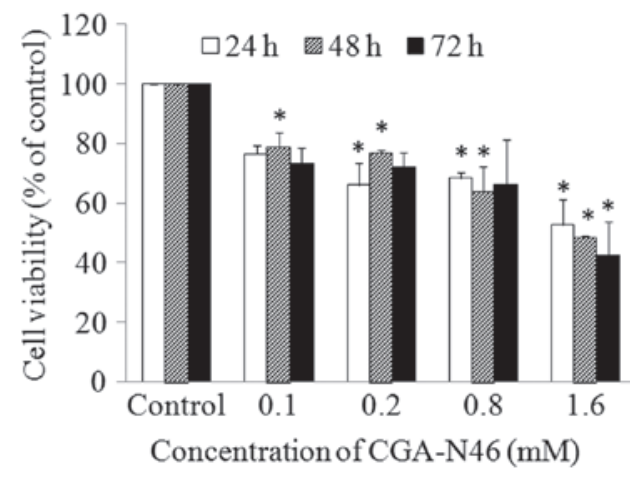

Figure 3. Effect of CGA-N46 on the growth of lung cancer cells. The proliferative activity of A549 cells was assessed using MTT assay. Values are presented as the mean \pm standard error of at least three independent experiments. ${ }^{*} \mathrm{P}<0.01$ compared with control (one-way analysis of variance and subsequent Least Significant Difference and Duncan's tests).

fungi in the local microenvironment of the human body may neutralize the alkaline cationic peptides, and thus impede the electrostatic attraction of the AMPs with fungal outer phospholipid membranes (32). CGA-N46 has almost zero charge at physiological $\mathrm{pH}$ due to its calculated $\mathrm{pI}$ of 7.38 ; therefore, it has a broad spectrum of $\mathrm{pH}$ stability. CGA-N46 may be a 

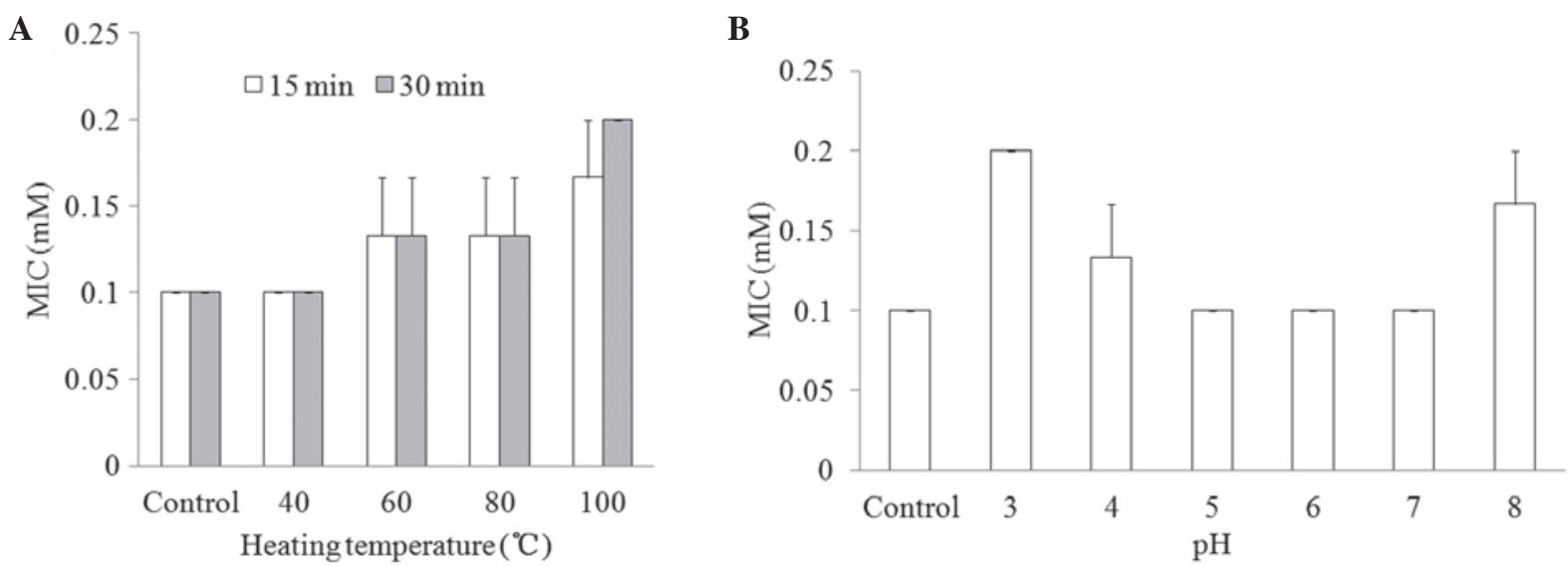

Figure 4. Effect of physicochemical factors on the stability of the antifungal activity of CGA-N46 against $C$. krusei. (A) The heat stability of CGA-N46 was assessed by comparing the MICs of CGA-N46 following treatment at different temperatures for $30 \mathrm{~min}$. (B) The pH stability of CGA-N46 was indicated by the MICs of CGA-N46 following treatment in different $\mathrm{pH}$ environments. MIC, minimum inhibitory concentration.
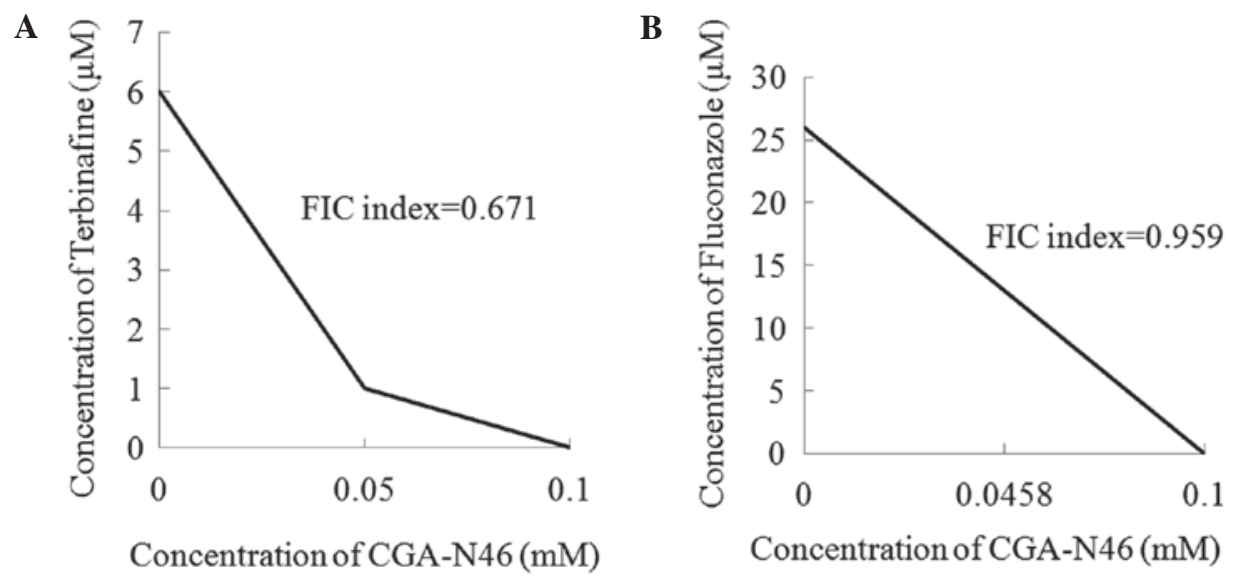

Figure 5. Checkerboard analysis of the activity of CGA-N46 plus antibiotics against $C$. krusei. The lowest concentration of each drug combination with growth inhibitory activity (minimum inhibitory concentration) is shown for (A) CGA-N46 combined with terbinafine and (B) CGA-N46 combined with fluconazole. An FIC index of $>0.5$ and $\leq 1$ denotes an additive combination. FIC, fractional inhibitory concentration.

good model for researching the mechanisms of non-cationic AMPs.

CGA-N46 exerted an antiproliferative effect on Candida spp. and A549 cancer cells in a concentration- and time-dependent manner. It had no hemolytic activity at the MIC of CGA-N46 against yeasts. Furthermore, the results showed that CGA-N46 had no significant effect on normal primary $\mathrm{CEF}$ cells at a concentration of $1.6 \mathrm{mM}$ and a reversible effect at concentrations $<1.6 \mathrm{mM}$. This observation was consistent with that for Magainin II (33). CGA-N46 therefore represents a member of a novel, non-cationic, $\alpha$-helical peptide family with antimicrobial and anticancer activities but without toxicity to erythrocytes, indicating the possibility for use in treatment for infection and cancer.

AMPs have different mechanisms of action from conventional antibiotics $(14,15)$. Previous studies have indicated that the limitations of AMPs, which are long amino acid sequences, are poor bioavailability and susceptibility to protease degradation and pathogen targeting $(14,17)$. To overcome these limitations, combination with conventional antibiotics or other compounds is generally used. Combined with minocycline or azole antifungal agents, lactoferricin has synergistic effects against an antibiotic-resistant strain of Staphylococcus aureus (34). The bactericidal effect was enhanced when human $\beta$-defensin was used in combination with the antimicrobial agents (17). Fluconazole and terbinafine are two antibiotics to which Candidas are prone to be resistant (35). In the present study, CGA-N46 was combined with these two drugs. In the checkerboard assay, the combination of CGA-N46 with each of the drugs exhibited enhanced antifungal activity. The combinations of CGA-N46 with terbinafine and fluconazole demonstrated additive effects against $C$. krusei. The results of this study may prove in the clinical application of AMPs in combination with other compounds.

\section{Acknowledgements}

This study was supported by the National Science Foundation of China (grant nos. 31071922, 31271948 and 21306040) and Henan University of Technology (no. 11JCYJ10). The authors would like to express their appreciation to Dr Jin Huang of Henan University of Technology for performing the SPSS analysis. 


\section{References}

1. Bassetti M, Taramasso L, Nicco E, Molinari MP, Mussap M and Viscoli C: Epidemiology, species distribution, antifungal susceptibility and outcome of nosocomial candidemia in a tertiary care hospital in Italy. PLoS One 6: e24198, 2011.

2. Ortega M, Marco F, Soriano A, Almela M, Martínez JA, López J, Pitart C and Mensa J: Candida species bloodstream infection: Epidemiology and outcome in a single institution from 1991 to 2008. J Hosp Infect 77: 157-161, 2011.

3. Scorzoni L, de Lucas MP, Mesa-Arango AC, Fusco-Almeida AM, Lozano E, Cuenca-Estrella M, Mendes-Giannini MJ and Zaragoza O: Antifungal efficacy during Candida krusei infection in non-conventional models correlates with the yeast in vitro susceptibility profile. PLoS One 8: e60047, 2013.

4. Gudlaugsson O, Gillespie S, Lee K, Vande Berg J, Hu J, Messer S, Herwaldt L, Pfaller M and Diekema D: Attributable mortality of nosocomial candidemia, revisited. Clin Infect Dis 37: 1172-1177, 2003.

5. Wisplinghoff H, Bischoff T, Tallent SM, Seifert H, Wenzel RP and Edmond MB: Nosocomial bloodstream infections in US hospitals: Analysis of 24,179 cases from a prospective nationwide surveillance study. Clin Infect Dis 39: 309-317, 2004.

6. Pushpanathan M, Rajendhran J, Jayashree S, Sundarakrishnan B, Jayachandran S and Gunasekaran P: Direct cell penetration of the antifungal peptide, MMGP1, in Candida albicans. J Pept Sci 18: 657-660, 2012.

7. Trick WE, Fridkin WE, Edwards SK, Hajjeh JR, Gaynes RA and National RP; Nosocomial Infections Surveillance System Hospitals: Secular trend of hospital-acquired candidemia among intensive care unit patients in the United States during 1989-1999. Clin Infect Dis 35: 627-630, 2002.

8. Arendrup MC: Epidemiology of invasive candidiasis. Curr Opin Crit Care 16: 445-452, 2010.

9. Pemán J, Cantón E, Quindós G, Eraso E, Alcoba J, Guinea J, Merino P, Ruiz-Pérez-de-Pipaon MT, Pérez-del-Molino L, Linares-Sicilia MJ, et al; FUNGEMYCA Study Group; Epidemiology, species distribution and in vitro antifungal susceptibility of fungaemia in a Spanish multicentre prospective survey. J Antimicrob Chemother 67: 1181-1187, 2012.

10. Leroy O, Gangneux JP, Montravers P, Mira JP, Gouin F, Sollet JP, Carlet J, Reynes J, Rosenheim M, Regnier B and Lortholary O; AmarCand Study Group: Epidemiology, management and risk factors for death of invasive Candida infections in critical care: A multicenter, prospective, observational study in France (2005-2006). Crit Care Med 37: 1612-1618, 2009.

11. Muñoz P, Sánchez-Somolinos M, Alcalá L, Rodríguez-Créixems M, Peláez T and Bouza E: Candida krusei fungaemia: Antifungal susceptibility and clinical presentation of an uncommon entity during 15 years in a single general hospital J Antimicrob Chemother 55: 188-193, 2005.

12. Lata S, Mishra N and Raghava G: AntiBP2: Improved version of antibacterial peptide prediction. BMC Bioinformatics 11 (Suppl 1): S19, 2010.

13. Lu J and Chen ZW: Isolation, characterization and anti-cancer activity of SK84, a novel glycine-rich antimicrobial peptide from Drosophila virilis. Peptides 31: 44-50, 2010.

14. Güell I, Micaló L, Cano L, Badosa E, Ferre R, Montesinos E, Bardají E, Feliu L and Planas M: Peptidotriazoles with antimicrobial activity against bacterial and fungal plant pathogens. Peptides 33: 9-17, 2012.

15. Hancock RE: Peptide antibiotics. Lancet 349: 418-422, 1997.

16. Foubister V: Superpeptide to treat Candida albicans. Drug Discov Today 8: 380-381, 2003.

17. Maisetta G, Batoni G, Esin S, Luperini F, Pardini M, Bottai D, Florio W, Giuca MR, Gabriele M and Campa M: Activity of human beta-defensin 3 alone or combined with other antimicrobial agents against oral bacteria. Antimicrob Agents Chemother 47: 3349-3351, 2003.
18. Eiden LE: Is chromogranin a prohormone? Nature 325: 301, 1987.

19. Lugardon K, Raffner R, Goumon Y, Corti A, Delmas A, Bulet P, Aunis D and Metz-Boutigue MH: Antibacterial and antifungal activities of vasostatin-1, the N-terminal fragment of chromogranin A. J Biol Chem 275: 10745-10753, 2000.

20. Lugardon K, Chasserot-Golaz S, Kieffer AE, Maget-Dana R, Nullans G, Kieffer B, Aunis D and Metz-Boutigue MH: Structural and biological characterization of chromofungin, the antifungal chromogranin A-(47-66)-derived peptide. J Biol Chem 276: 35875-35882, 2001.

21. Briolat J, Wu SD, Mahata SK, Gonthier B, Bagnard D, Chasserot-Golaz S, Helle KB, Aunis D and Metz-Boutigue MH: New antimicrobial activity for the catecholamine release-inhibitory peptide from chromogranin A. Cell Mol Life Sci 62: 377-385, 2005.

22. Radek KA, Lopez-Garcia B, Hupe M, Niesman IR, Elias PM, Taupenot L, Mahata SK, O'Connor DT and Gallo RL: The neuroendocrine peptide catestatin is a cutaneous antimicrobial and induced in the skin after injury. J Invest Dermatol 128: 1525-1534, 2008.

23. Li R, Zhang T, Luo J, Wang F, Gu Q, Gan J and Xiao F: Antifungal activity fragments of $\mathrm{N}$ domain of chromogranin A. Zhong Shan Da Xue Xue Bao 45: 64-67, 2006 (In Chinese).

24. Aleinein RA, Hamoud R, Schäfer H and Wink M: Molecular cloning and expression of ranalexin, a bioactive antimicrobial peptide from Rana catesbeiana in Escherichia coli and assessments of its biological activities. Appl Microbiol Biotechnol 97: 3535-3543, 2013.

25. Mochon AB and Liu H: The antimicrobial peptide histatin-5 causes a spatially restricted disruption on the Candida albicans surface, allowing rapid entry of the peptide into the cytoplasm. PLoS Pathog 4: e1000190, 2008.

26. Kong BW, Lee J, Bottje WG, Lassiter K, Lee J, Gentles LE, Chandra YG and Foster DN: Microarray analysis of early and late passage chicken embryo fibroblast cells. Poult Sci 92: 770-781, 2013.

27. National Committee for Clinical Laboratory Standards (NCCLS): Reference method for broth dilution antifungal susceptibility testing of yeasts: Approved standard. 2nd edition. NCCLS, Wayne, USA, pp1-13, 1997.

28. Huang J, Hao D, Chen Y, Xu Y, Tan J, Huang Y, Li F and Chen Y: Inhibitory effects and mechanisms of physiological conditions on the activity of enantiomeric forms of an $\alpha$-helical antibacterial peptide against bacteria. Peptides 32: 1488-1495, 2011.

29. Su Y, Ma L, Wen Y, Wang H and Zhang S: Studies of the in vitro antibacterial activities of several polyphenols against clinical isolates of methicillin-resistant Staphylococcus aureus. Molecules 19: 12630-12639, 2014.

30. Eliopoulos GM and Moellering RC: Antimicrobial combinations. In: Antibiotics in Laboratory Medicine. Lorian V (ed.). Williams and Wilkins, Baltimore, MD, pp432-492, 1991.

31. Hancock RE and Diamond G: The role of cationic antimicrobial peptides in innate host defences. Trends Microbiol 8: 402-410, 2000.

32. Tlaskalová-Hogenová H, Stepánková R, Hudcovic T, Tucková L, Cukrowska B, Lodinová-Zádníková R, Kozáková H, Rossmann P, Bártová J, Sokol D, et al: Commensal bacteria (normal microflora), mucosal immunity and chronic inflammatory and autoimmune diseases. Immunol Lett 93: 97-108, 2004.

33. Lehmann J, Retz M, Sidhu SS, Suttmann H, Sell M, Paulsen F, Harder J, Unteregger G and Stöckle M: Antitumor activity of the antimicrobial peptide magainin II against bladder cancer cell lines. Eur Urol 50: 141-147, 2006.

34. Wakabayashi H, Teraguchi S and Tamura Y: Increased Staphylococcus-killing activity of an antimicrobial peptide, lactoferricin B, with minocycline and monoacylglycerol. Biosci Biotechnol Biochem 66: 2161-2167, 2002.

35. Olafsson JH, Sigurgeirsson B and Baran R: Combination therapy for onychomycosis. Br J Dermatol 149: 15-18, 2003. 